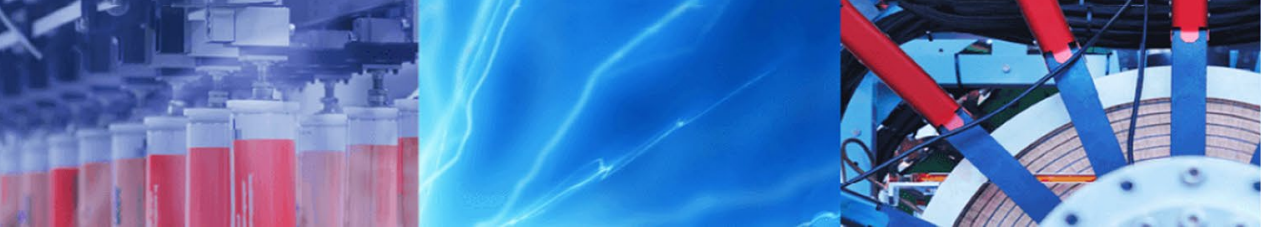

Research Article

\title{
Historical analysis of domestic wastewater pollution and its measures in Lake Teganuma basin using surfactant concentrations recorded in sediment core samples
}

\author{
Natsuki Sampei ${ }^{1} \cdot$ Keigo Matsumoto $^{1} \cdot$ Chiaki Mihara $^{1} \cdot$ Seigo Sakurai $^{1} \cdot$ Tomokazu Takeuchi $^{1} \cdot$ Yumiko Ohkouchi $^{1}$. \\ Kazutoshi Sugita ${ }^{2} \cdot$ Kazuho Inaba $^{1}$ (D)
}

(c) Springer Nature Switzerland AG 2019

\begin{abstract}
In order to learn whether it is possible to clarify the history of water pollution and its countermeasure from the fluctuation of chemicals accumulated in the sediment core of the lake, concentrations of linear alkylbenzenesulfonates (LAS) in sediment core samples collected from Lake Teganuma, which was severely polluted by domestic wastewater, were determined. The results were compared with concentrations of LAS in the lake water, waters of two large inflowing rivers, and in sewage from the Lake Teganuma basin. Sediment cores collected in 2003 and 2004 recorded the history of domestic wastewater pollution in the basin during the previous 25-35 years. LAS concentrations in the sediment core drastically decreased after the 1990s, and similar reductions of LAS were observed in the river and lake waters. Large amounts of LAS have still been used in the basin during 1980s to 2017, the drastic decrease of LAS concentrations in both the sediment and the river and lake waters is attributable the expansion of sewer system coverage in the basin since 1981. The effect of lake dredging was also estimated by the changes in surfactant concentrations. Thus, historical changes in not only pollution levels but also social factors can be assessed by determining sediment concentrations of chemicals in daily use such as LAS.
\end{abstract}

Keywords Pollution history · Domestic wastewater · Sewer system coverage · Sediment core $\cdot$ Linear and branched alkylbenzenesulfonates

\section{Introduction}

Knowledge of how pollution levels in water bodies have fluctuated over time in relation to changes in social factors affecting the surrounding region is expected to be useful for predicting future pollution levels and for formulating conservation measures. Pollution of aquatic environments is generally caused by the inflow of pollutants from upstream sources, and the amounts of inflowing pollutants typically fluctuate, making it difficult to estimate past concentrations of pollutants from present values. Because long-term water quality monitoring has not been conducted in many aquatic areas, a method for estimating past levels of contamination is needed.

Bottom sediments of lakes are typically age-stratified, and each layer can adsorb hydrophobic pollutants at that occasion. Therefore, the history of pollution in a lake basin can be reconstructed by investigating pollutant concentrations recorded in the bottom sediments. Many studies have reported the history of contamination by synthetic chemicals such as polychlorinated biphenyls (PCBs), dioxins, and perfluorocarbons (PFCs) from their concentration fluctuations in sediment [1-4].

\footnotetext{
$\triangle$ Kazuho Inaba, inaba@azabu-u.ac.jp| ${ }^{1}$ Department of Environmental Science, Azabu University, 1-17-71 Fuchinobe, Chuo-ku, Sagamihara, Kanagawa 252-5201, Japan. ${ }^{2}$ Department of Veterinary Medicine, Azabu University, 1-17-71 Fuchinobe, Chuo-ku, Sagamihara, Kanagawa 252-5201, Japan.
} 
The aim of this study is to assess whether historic changes in social factors such as population, consumption trends, and effectiveness of several water purification systems can be inferred from concentration profiles of indicator chemicals in bottom sediment core samples. If it is possible, it may help to make better measures against the pollutions. For this purpose, we used synthetic detergent as an indicator of pollution history. Unlike compounds that are unintentionally produced and discharged, or not used on a daily basis, such as dioxins and PFCs, domestically used synthetic detergents are used and discharged in known amounts every day $[5,6]$. As a result, they can be effectively used to quantify the areal spread of domestic wastewater pollution in aquatic environments [5, 7-9]. However, to date, synthetic detergents have not been used to estimate long-term changes in social factors in an aquatic basin.

As a pollution indicator, we selected sodium alkylbenzenesulfonates, which are a main component of synthetic laundry detergents. Beginning in the 1950s, branched sodium alkylbenzenesulfonates (ABS) were widely used in Japan as anionic surfactants in synthetic detergents. However, because ABS degrade very slowly, they tend to remain in environmental waters, where they cause foam to form on both natural water and wastewater surfaces, resulting in both esthetic damage and deterioration of sewage treatment efficiency. To address this problem, ABS were replaced in 1971 by easily degradable sodium linear alkylbenzenesulfonates (LAS) in Japan. LAS readily degrade under aerobic conditions, but they are hardly degradable in anaerobic environments [10-13]; as a result, LAS that have been adsorbed onto lake sediment particles are expected to remain in the sediment layer for a long time. Furthermore, because the switch from ABS to LAS was done all at once in 1971, the presence of ABS or LAS in sediment core samples indicates whether the sediment was deposited before or after that date.

\section{Materials and methods}

\subsection{Field investigation site and sampling sediments and waters}

The field investigation was conducted in Lake Teganuma $\left(35^{\circ} 51^{\prime} 24^{\prime \prime} \mathrm{N}, 140^{\circ} 1^{\prime} 54^{\prime \prime} \mathrm{E}\right)$, which is $30 \mathrm{~km}$ northeast of central Tokyo, between the suburbs of Abiko and Kashiwa (Fig. 1). The lake has $4.0 \mathrm{~km}^{2}$ of surface area, $0.9 \mathrm{~m}$ of average depth, and its catchment area is $144 \mathrm{~km}^{2}$. Main inflowing streams are Oohori and Ootsu Rivers, and outflowing stream is Teganuma River. According to the Chiba Prefectural Government, the population in the catchment area increased from about 100,000 residents in 1960 to about
520,000 in 2015 [14]. At present, about $60 \%$ of the total basin area is residential. Increase in domestic wastewater from the basin by increase in the population in the basin caused serious contamination of Lake Teganuma in the past. The demographics results of neighboring municipalities from 1960 till 2018 are summarized in Table 1. In fact, for 27 consecutive years, from 1974 to 2000, Lake Teganuma was regarded as the most polluted lake in Japan. For example, the average chemical oxygen demand (COD) of the lake water in 1985 was about 24 mg/L [14]. Lake Teganuma is a suitable site for a comparative study because of the availability of limnological and sociological data from previous research in the basin [14-18].

The bottom sediment samples were collected with an acrylic tube core sampler $(6 \mathrm{~cm} \phi \times 50 \mathrm{~cm})$ at four sites (Sts. A1, B1, C, and D) on 24 October 2003 and at two sites (Sts. $A 2$ and B2) on 28 October 2004. Sites A1 and A2 are at the mouth of the Oohori River at the west end of the upper lake, Sts. B1 and B2 are at the mouth of the Ootsu River on the south side of the upper lake, St. $C$ is in the center of the upper lake, and St. D is in the center of the lower lake (Fig. 1). The collected sediment core samples $(35 \mathrm{~cm}$ length for Sts. A1, B1, C, and D and $37.5 \mathrm{~cm}$ length for Sts. $A 2$ and B2) were placed in ice for transport to the laboratory, where within $4 \mathrm{~h}$ of collection they were cut into 5-cm-thick (Sts. A1, B1, C, and D) or 2.5-cm-thick (Sts. A2 and B2) slices. The slices were freeze-dried and stored until analysis.

River water samples were collected in a polypropylene beaker at Kitakashiwa Bridge on the Oohori River (St. H, $1000 \mathrm{~m}$ upstream from St. A2) and at Hidori Bridge on the Ootsu River (St. T, 300 m upstream from Sts. B1 and B2) on 6 May, 3 July, 1 September, and 8 November 2016, and 10 January, 6 March, 16 May, and 31 July 2017. Influent sewage samples were collected in a stainless steel bucket from the first settling tank of the Teganuma basin wastewater treatment plant (St. W) on 8 November 2016 and on 6 March and 31 July 2017. The collected water and sewage samples were filtered through a glass fiber filter with a 10- $\mu \mathrm{m}$ pore size (Whatman, GF/C) just after collection at each site, and the filtered samples were placed in ice for transport to the laboratory.

\subsection{Determination of LAS and ABS}

LAS and ABS in the sediment, water, and sewage samples were determined as described previously [15]. Commercially used LAS and ABS are mixtures of homologs with alkyl chain lengths of 11-14; moreover, each homolog is a mixture of isomers with a different phenyl-substituted site on the alkyl chain. The chemicals in the sediment and water samples were separated and quantified by HPLC (L-6200 liquid chromatograph with an L-2400 UV detector 


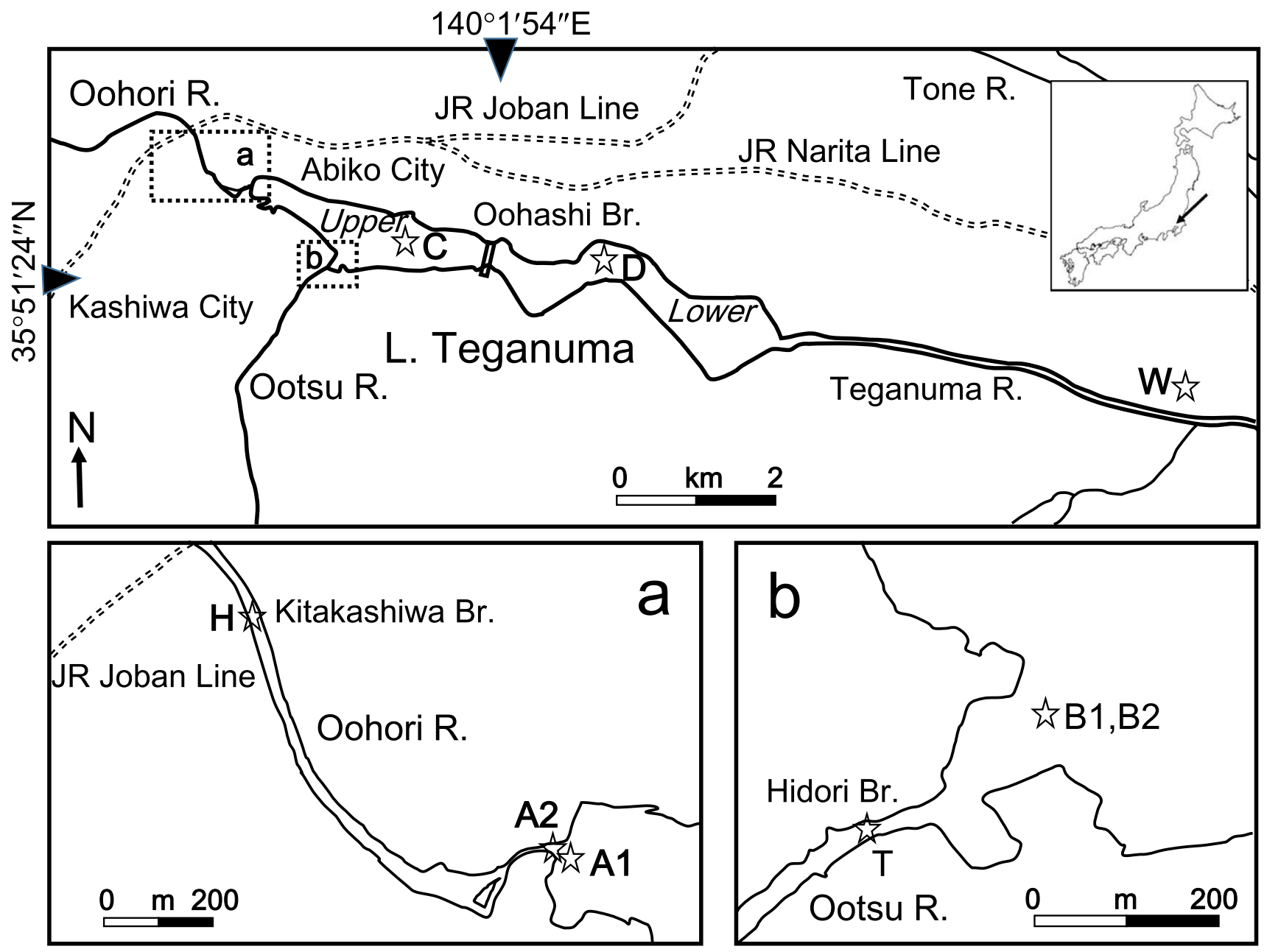

Fig. 1 Maps showing the location of the Lake Teganuma basin and the sampling sites. Maps a and b show the areas around the mouth of the Oohori River and Ootsu River, respectively. Stars indicate sites where bottom sediment ( $A 1, A 2, B 1, B 2, C$, and $D)$, river water $(\mathrm{H}$ and $\mathrm{T})$, and wastewater treatment plant influent $(\mathrm{W})$ were sampled and a D-2500 data processor; Hitachi High Technologies Co.).

LAS and ABS were extracted from the freeze-dried sediment samples by a supersonic extraction method as follows. One gram of sample was put into a stoppered glass tube, and $10 \mathrm{~mL}$ of methanol was added. The mixture was agitated in a supersonic bath for $30 \mathrm{~min}$ and then centrifuged $10 \mathrm{~min}$ at $2500 \mathrm{rpm}$. Then, the supernatant methanol solution was collected in a volumetric flask. The extraction procedure was repeated three times, and the collected solution was filtered through a membrane with a 0.2- $\mu \mathrm{m}$ pore size (Chromato disk 25A, GL Science Co.). The filtered methanol solution was diluted 10 times with Milli Q water and used for LAS and ABS determination in the sediment samples.

The LAS and ABS in aqueous solution were analyzed as follows: A certain volume of aqueous sample (sediment extract, river water, or wastewater) was put into a stoppered glass tube; potassium chloride was added to make a $0.25 \mathrm{M}$ solution, and then, the same volume of 4-methyl-2-pentanone (MIBK) was added. The tube was first mechanically agitated vigorously for $10 \mathrm{~min}$ and then centrifuged $10 \mathrm{~min}$ at $2500 \mathrm{rpm}$. A portion of the MIBK solution was then transferred to another stoppered glass tube. The same volume of Milli $Q$ water and 5 times $(\mathrm{v} / \mathrm{v})$ of hexane were added, and then agitated for $10 \mathrm{~min}$, and centrifuged $10 \mathrm{~min}$ at $2500 \mathrm{rpm}$. After centrifugation, the aqueous phase was collected and LAS and ABS in the solution were separated by a gradient elution technique using acetonitrile and $0.02 \mathrm{M}$ aqueous sodium perchlorate solutions in a Shim-pak CLC-ODS reversed phase column (Shimadzu Co.). LAS and ABS analogs were measured by UV absorption at $225 \mathrm{~nm}$.

Extraction from the sediment sample was performed at least duplicate for the same depth at the same location, and HPLC measurement was performed duplicate 
Table 1 Demographics results of neighboring municipalities around Lake Teganuma

\begin{tabular}{|c|c|c|c|c|c|c|}
\hline \multirow[t]{2}{*}{ Year } & \multicolumn{6}{|c|}{ Population in municipality (person) } \\
\hline & Kashiwa $^{\mathrm{a}}$ & Abiko $^{b}$ & Matsudo $^{c}$ & Nagareyama $^{d}$ & $\operatorname{lnzai}^{\mathrm{e}}$ & Kamagaya $^{f}$ \\
\hline 1960 & 63,745 & 27,063 & 19,656 & $\mathrm{ND}^{\mathrm{g}}$ & $\mathrm{ND}^{\mathrm{g}}$ & $\mathrm{ND}^{\mathrm{g}}$ \\
\hline 1965 & 109,237 & 33,216 & 41,913 & $\mathrm{ND}^{\mathrm{g}}$ & $\mathrm{ND}^{\mathrm{g}}$ & $\mathrm{ND}^{\mathrm{g}}$ \\
\hline 1970 & 160,635 & 49,240 & 70,829 & $\mathrm{ND}^{\mathrm{g}}$ & $\mathrm{ND}^{\mathrm{g}}$ & $\mathrm{ND}^{\mathrm{g}}$ \\
\hline 1975 & 203,065 & 76,218 & 344,558 & 79,003 & 16,833 & 63,288 \\
\hline 1980 & $\mathrm{ND}^{\mathrm{g}}$ & $N^{g}$ & 400,863 & 103,861 & 17,869 & 76,157 \\
\hline 1985 & 273,128 & 111,659 & 427,473 & 121,198 & 23,833 & 85,705 \\
\hline 1990 & $301,230^{\mathrm{h}}$ & $120,628^{h}$ & 456,210 & 137,317 & 41,718 & 95,052 \\
\hline 1995 & 317,750 & 124,257 & 461,503 & 144,863 & 57,667 & 99,694 \\
\hline 2000 & 323,865 & $N D^{g}$ & 464,609 & $\mathrm{ND}^{g}$ & $\mathrm{ND}^{\mathrm{g}}$ & $\mathrm{ND}^{\mathrm{g}}$ \\
\hline 2005 & 380,963 & 131,205 & 472,579 & 150,910 & $\mathrm{ND}^{\mathrm{g}}$ & 102,812 \\
\hline 2010 & 404,012 & 134,017 & 484,457 & 161,258 & 88,176 & 107,853 \\
\hline 2018 & 422,385 & 132,231 & 490,632 & 189,885 & 101,299 & 109,439 \\
\hline \multicolumn{7}{|c|}{ All these municipalities are partly included in catchment area of Lake Teganuma } \\
\hline \multicolumn{7}{|c|}{ a http://www.city.kashiwa.lg.jp/soshiki/020800/p008853.html\#03_kokusei } \\
\hline \multirow{3}{*}{\multicolumn{7}{|c|}{$\begin{array}{l}\text { bhttps://www.city.abiko.chiba.jp/shisei/toukeijoho/toukei/abikoshi/2004_2014.files/2017toukeisyo.pdf } \\
\text { chttps://www.city.matsudo.chiba.jp/profile/jinkoutoukei/jinkou/jyoujyu/suii.html } \\
\text { dhttps://www.city.nagareyama.chiba.jp/_res/projects/default_project/_page_/001/008/461/2jinnkouh2 } \\
\text { 9.pdf }\end{array}$}} \\
\hline & & & & & & \\
\hline & & & & & & \\
\hline \multicolumn{7}{|c|}{ ehttp://www.city.inzai.Ig.jp/cmsfiles/contents/0000007/7762/2017_00_Datainzai_All.pdf } \\
\hline \multicolumn{7}{|c|}{$\begin{array}{l}\text { fhttp://www.city.kamagaya.chiba.jp/sesakumidashi/toukei-info/111011101110a2018121.files/h29to } \\
\text { ukei.pdf }\end{array}$} \\
\hline \multicolumn{7}{|c|}{${ }^{9}$ No data were reported } \\
\hline \multicolumn{7}{|c|}{ h Data obtained in 1989} \\
\hline
\end{tabular}

on the same sample solution. The detection limit of each analog was $10 \mathrm{ng}$.

\section{Results and discussion}

\subsection{LAS and ABS concentrations in Lake Teganuma sediments}

The concentration of each LAS or ABS analog was separately obtained by HPLC measurement [15], and the total concentration of LAS or ABS in each sediment sample was determined by summing the analog concentrations. Then, we examined the vertical distributions of total LAS and total ABS concentrations in the sediment samples at Sts. A1 to D (Fig. 2a-d). The LAS sediment concentration profile differed among the sampling sites; concentrations of LAS were very high at around 15-35 cm depth at Sts. A2, B1, and B2, but they were remarkably low at all depths at Sts. A1, C, and D. In all samples collected at these six sites, the concentration of $A B S$ was below the detection limit.

\subsection{LAS concentrations contained in water samples from the Lake Teganuma basin}

LAS concentrations at the two river sites and in the influent of the wastewater treatment plant were monitored for 1 year in this study (Table 2), and the results were compared with previously measured LAS concentrations at the two river sites (Sts. $\mathrm{H}$ and T), at a site about $600 \mathrm{~m}$ downstream from Sts. $A 1$ and $A 2$, and at the outlet of the lake $[15,17]$.

The concentrations of LAS at the two river sites were very low during 2016-2017, one-tenth the magnitude of concentrations measured in 2005 and one-twentieth to one-fiftieth the magnitude of concentrations measured during 1987-1988 (Table 2). Thus, the LAS load entering Lake Teganuma from the two rivers decreased over a period of about 30 years. In contrast to the low concentrations in river water, the LAS concentration in 2016-2017 was very high in the influent of the wastewater treatment plant. Therefore, LAS was still a main component of detergents used domestically in the basin. The measured concentrations in the sewage are similar in 

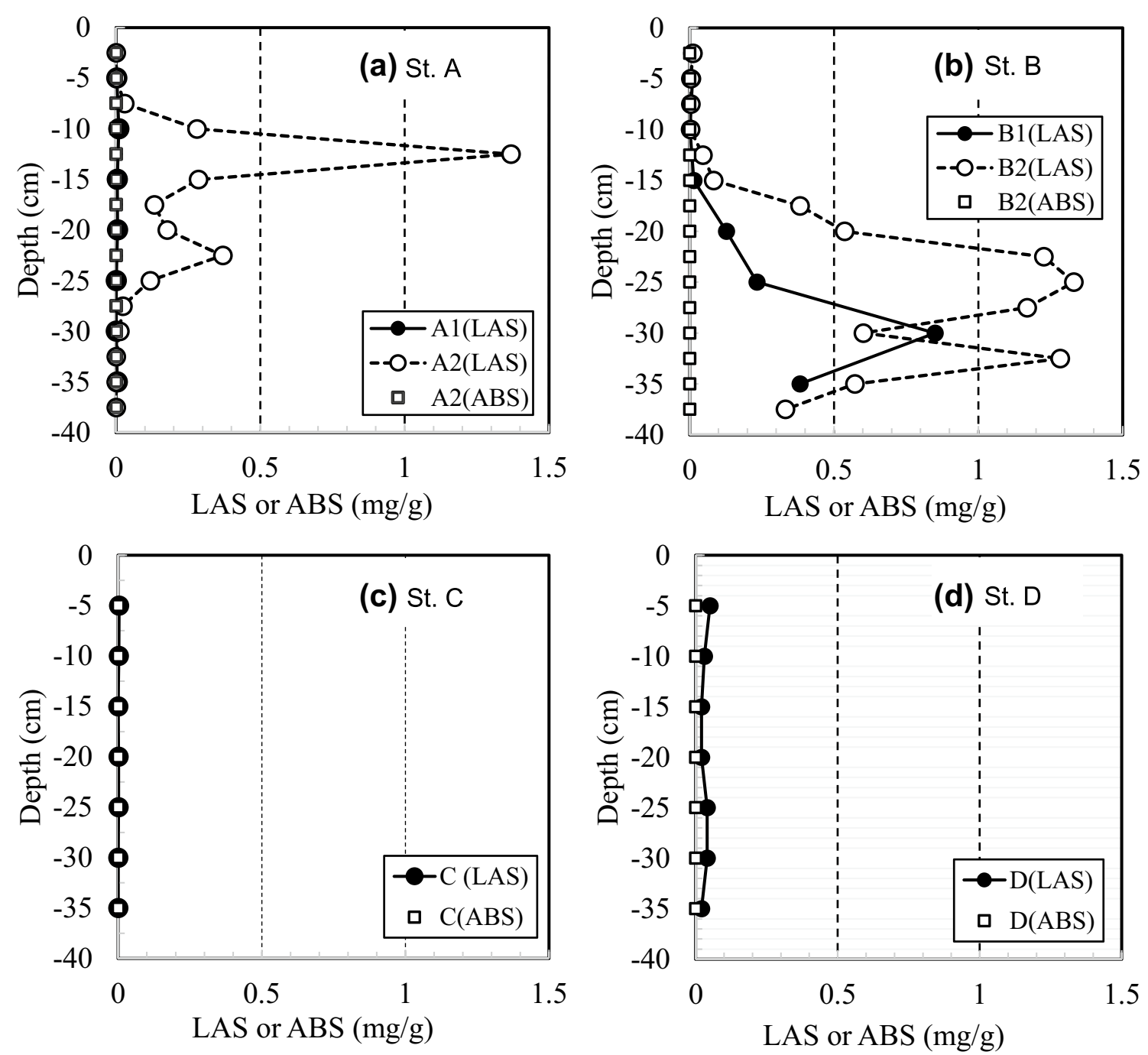

Fig. 2 Concentration profiles of total LAS and total ABS in the bottom sediment samples collected in Lake Teganuma. a St. A, b St. B, c St. C, and $\mathbf{d}$ St. D. The vertical axes show depth below the bottom surface

Table 2 LAS concentrations $(\mathrm{mg} / \mathrm{L})$ in water samples from the Lake Teganuma basin

\begin{tabular}{|c|c|c|c|c|c|}
\hline \multirow[t]{2}{*}{ Period of investigation } & \multicolumn{2}{|l|}{ River } & \multirow{2}{*}{$\begin{array}{l}\text { WTPa } \\
\text { St. W }\end{array}$} & \multicolumn{2}{|c|}{ L. Teganuma } \\
\hline & St. H & St. T & & Inlet $^{b}$ & Outlet \\
\hline $1986-1987^{c}$ & $N^{d}$ & $N^{d}$ & $N D^{d}$ & $0.01-0.6$ & $0-0.2$ \\
\hline $1987-1988^{e}$ & $0.4-1.5$ & $N D^{d}$ & $N D^{d}$ & $0.01-0.7$ & $0-0.3$ \\
\hline $2005^{f}$ & 0.3 & 0.1 & $N D^{d}$ & $\mathrm{ND}^{\mathrm{d}}$ & $\mathrm{ND}^{\mathrm{d}}$ \\
\hline $2016-2017^{9}$ & $0.00-0.03$ & $0.00-0.02$ & $1.28-2.16$ & $N^{d}$ & $N^{d}$ \\
\hline
\end{tabular}

${ }^{a}$ Teganuma basin wastewater treatment plant

${ }^{\mathrm{b}}$ About $600 \mathrm{~m}$ downstream from Sts. A1 and A2

'From [15]

${ }^{\mathrm{d}}$ Not determined

eFrom [17]

f Sample collected on 10 December 2005 by K. Inaba and T. Doi

gPresent work 
magnitude to concentrations reported for other wastewater treatment plants in Japan [19].

\subsection{Estimating the history of domestic wastewater pollution in Lake Teganuma}

Although water flow above the bottom surface of a lake can resuspend sediment and disturb the underlying stratified sediments, we analyzed the sediment data by assuming that this disturbance was negligible. The deposition rate of bottom sediment at Sts. A1-D was estimated, as described by the Chiba Prefectural Laboratory of Water Pollution [20], from the thickness of the top blackish polluted sediment layer overlying layers composed of sand and clay. The reported thickness of the polluted layer was $25 \mathrm{~cm}$ at the mouth of the Oohori River, $22.5 \mathrm{~cm}$ at the mouth of the Ootsu River, and $15 \mathrm{~cm}$ in the center of both the upper lake and the lower lake. The sampling of the bottom sediment of Lake Teganuma by the Chiba Prefectural Laboratory of Water Pollution was held in October 1980 [20] and the increase in domestic wastewater pollution by increasing the residential land use in the catchment area had been in progress since the 1960s, this polluted sediment layer probably accumulated over about a 15-year period following the beginning of residential development in the catchment area. Hamada et al. [21] measured the sediment deposition rate in lower Lake Teganuma by using ${ }^{210} \mathrm{~Pb}$ and ${ }^{137} \mathrm{Cs}$ isotopes and reported that the annual increment at four locations ranged from 0.6 to $1.3 \mathrm{~cm}$, values consistent with the annual deposition rate estimated from the thickness of polluted sediment layer in the present study. This similarity between two different methods shows that our estimated deposition rate is reasonable. In addition, the fact that no ABS was observed in all the sediment samples indicates the sediment had been deposited after 1971.
As described above, it is possible to determine the deposition age from the depth of the bottom sediment, if bottom sediment is age-stratified and there is no defect. Using the estimated sediment deposition rate, the depth of the sediment core sample in Fig. 2a- $d$ can be converted to the age, Fig. 3a-d. However, the lamination of the sediment is not established, the age we estimated does not correspond to the actual sediment layer. LAS was seemed to be deposited during 1990-2000 at St. A2, and during the 1980s to the mid-1990s at Sts. B1 and B2 (Fig. 3a-d). The period of greatest pollution differed somewhat among these three sites, although contamination of the sediments in the river-mouth area has decreased since the mid-1990s. Possible explanation for the difference in the pollution peak is described later.

The reduction of LAS pollution recorded in the sediment samples after the mid-1990s is well explained by the changes in LAS concentrations in the Oohori and Ootsu rivers (Table 2). There are two possible explanations for the decrease in LAS concentrations in both bottom sediments and water during the 30 years between 1986-1987 and 2016-2017: the residents in the basin may have stopped using detergents containing LAS, or they may have continued to use such detergents but the chemicals were not released into the river system. The high LAS concentration in the influent of the wastewater treatment plant in 2016-2017 (Table 2) clearly indicates that the residents continued to use LAS-containing detergents.

The per capita loading of LAS in the basin can be estimated from the LAS concentration in the influent wastewater, the population of the sewage system in the basin (570,000 in 2017), and the amount of water entering the wastewater treatment plant $\left(200,000 \mathrm{~m}^{3} /\right.$ day in 2017$)$ [22] We therefore calculated the per capita loading for domestically utilized LAS to be $0.6 \mathrm{~g} /$ day and the per capita volume of water used to be $350 \mathrm{~L} /$ day. In the late 1980 s, the
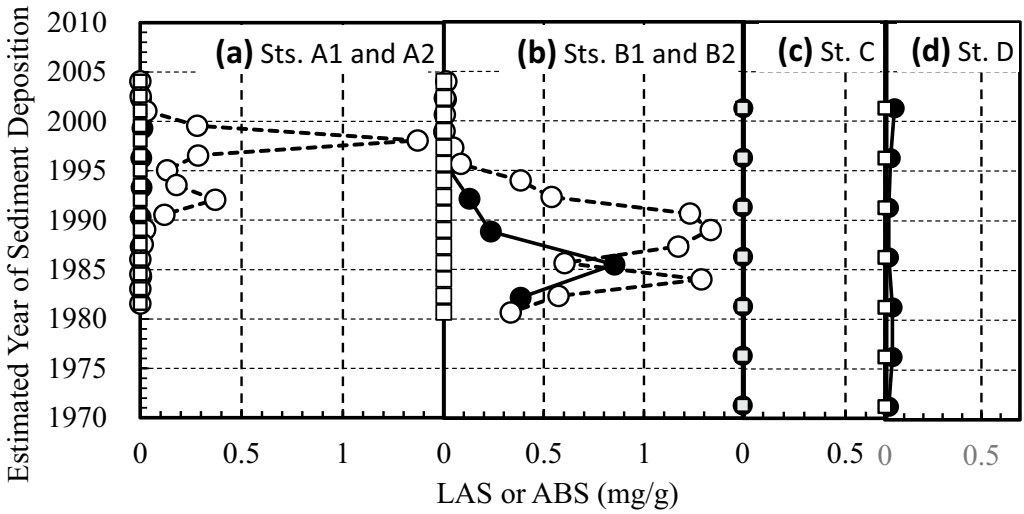

LAS or ABS $(\mathrm{mg} / \mathrm{g})$

Fig. 3 History of domestic wastewater pollution and countermeasures in the Lake Teganuma basin. Concentrations of LAS and ABS in bottom sediments at Sts. a $A 1$ and $A 2, \mathbf{b} B 1$ and $B 2, \mathbf{c} C$, and $\mathbf{d} D$.

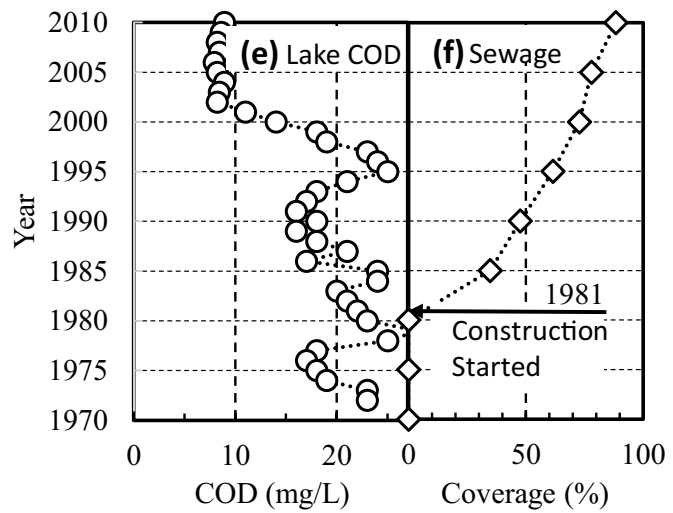

See Fig. 2a-d for explanation of the symbols. e Reported COD values of lake water [14]. $\mathbf{f}$ Coverage of the Teganuma basin sewage system [25] 
per capita loading for LAS was $1.0 \mathrm{~g} /$ day [23] and in 2015, it was $0.32-1.34 \mathrm{~g} /$ day [6]. The per capita volume of water used domestically has been reported to be 220 L/day [23] and 220-330 L/day [24]. The per capita loading of LAS estimated in this study may be somewhat lower and the per capita volume of water may be somewhat higher than those reported values. The differences may be explained that the sewage influent at the Teganuma basin wastewater treatment plant includes not only domestic wastewater but also drainage from offices, factories, and other sources but the previous reported values were limited to domestic wastewater. Therefore, the per capita volume of $350 \mathrm{~L} /$ day estimated above is an overestimate for domestic use, and the per capita loading for LAS may be an underestimate. Since these facts, the loading of LAS to Lake Teganuma since the late 1980s has not changed significantly and the decrease is mainly attributable to expansion of sewage system coverage in the basin. Construction of the Teganuma basin sewerage system started in 1981, and coverage reached 30\% in 1990 and $70 \%$ in 2000 [25] (Fig. 3f). The increase in coverage thus corresponds to the decrease of LAS concentrations in both the sediments and the rivers, and it is also consistent with the decrease in measured COD values in the lake from the 1990s [14] (Fig. 3a, b, e; Table 2).

Despite the construction of the sewerage system started in 1981, the peak of LAS pollution in the sediment core samples has appeared in the mid-1980s to the 1990s. The difference can be explained by a time lag between laying sewer and actually use it. In Japan, the construction of the main piping of the sewer is carried out by local governments, but since each household is responsible for connection from each home, there is some deviation for the utilization to rise. The difference is also explained that the population of the catchment area had still increased during 1981 to mid-1990s (Table 1). The total amount of LAS used in the basin was also increased; thus, the amount of LAS discharged directly to the rivers did not reduce drastically.

\subsection{Other reasons for LAS concentration changes in the sediments and water of Lake Teganuma}

\subsubsection{Dredging}

Bottom mud was regularly dredged at several points in upper Lake Teganuma from 1976 to 2005 [26], and this should affect the preservation state of the chemicals. During 1986-1987, LAS concentrations in the surface sediment at the inlet and outlet of the lake were $0.1-0.4 \mathrm{mg} / \mathrm{g}$ and $0-0.004 \mathrm{mg} / \mathrm{g}$, respectively [15]. Because Sts. A1 and $A 2$ are located about $600 \mathrm{~m}$ upstream from the inlet site of Inaba and Amano [15], the amounts of LAS adsorbed onto bottom sediments at Sts. A1 and A2 during the mid1980 s should be much higher than the inlet values. It is also true that more than $1 \mathrm{mg} / \mathrm{L}$ of LAS was detected in the river water in the latter half of the 1980s [17], the sediment should contain high concentrations of LAS. However, the LAS concentrations in the sediment at St. A1 and in samples from deeper than $15 \mathrm{~cm}$ (before the mid-1990s) at St. A2 were extremely low, probably because of the dredging.

Site $A 1$ is about 10 m east of the mouth of the Oohori River, and St. A2 is a few meters above the mouth. Dredging in the Oohori River mouth, including at St. A2, was conducted from 1977 to 1980 , and in 1993, and intermittent dredging was done in the lake area, including at St. A1, from 1980 to 2005 (personal communication, H. Ogura, 2005). This indicates that the sediment deposited before 1993 at St. A2 and that before 2003 at St. A1 was removed by dredging. Hence, all the sediment samples collected at St. A1 and the samples below $15 \mathrm{~cm}$ at $\mathrm{A} 2$ may be the sediment deposited before the pollution started and the speculated age has no meaning. In contrast, the very low LAS concentrations in sediment samples from 2000 and after at St. A2 site may reflect a decrease in the supply of LAS from the river water (see Table 2). The sampling sites near the Ootsu River mouth (Sts. B1 and B2) were not in a dredging area, so the long-term record of LAS pollution should be preserved in the sediments at those sites.

The LAS concentration was below the detection limit at all depths at St. C, in the center of the upper lake, whereas a small amount of LAS was detected at all depths at St. $D$, in the center of the lower lake. The main source of LAS in Lake Teganuma was the two rivers; hence, the surface water of upper lake was much polluted than that of the lower lake [15]. Nevertheless, the sediment at St. D was much polluted than that at $S$ t. C. These results may reflect the fact that although dredging was carried out only in the upper lake, sediment particles suspended by dredging may have settled to the bottom in the lower lake after flowing through with the lake water. That is why LAS is constantly preserved in the bottom sediment at St. D since the 1990s when the sewage system was maintained and pollution caused by direct discharge to the two rivers was resolved.

Using the results of consideration on the dredging in the lake, the depositional age map in the vertical direction of each sediment core sample was made (Fig. 4).

\subsubsection{Conduction}

In 2000, the North Chiba Conduction Project was started to improve the water quality in Lake Teganuma [27] by diverting water from the Tone River into Lake Teganuma. Water from the Tone River is introduced at a flow rate of up to $1 \mathrm{~m}^{3} / \mathrm{s}$ into the upper Oohori River and at a rate of 
Fig. 4 Depositional age map in the vertical direction of each sediment core sample estimated by the sediment deposition rate at each site and the loss of the bottom sediment by dredging

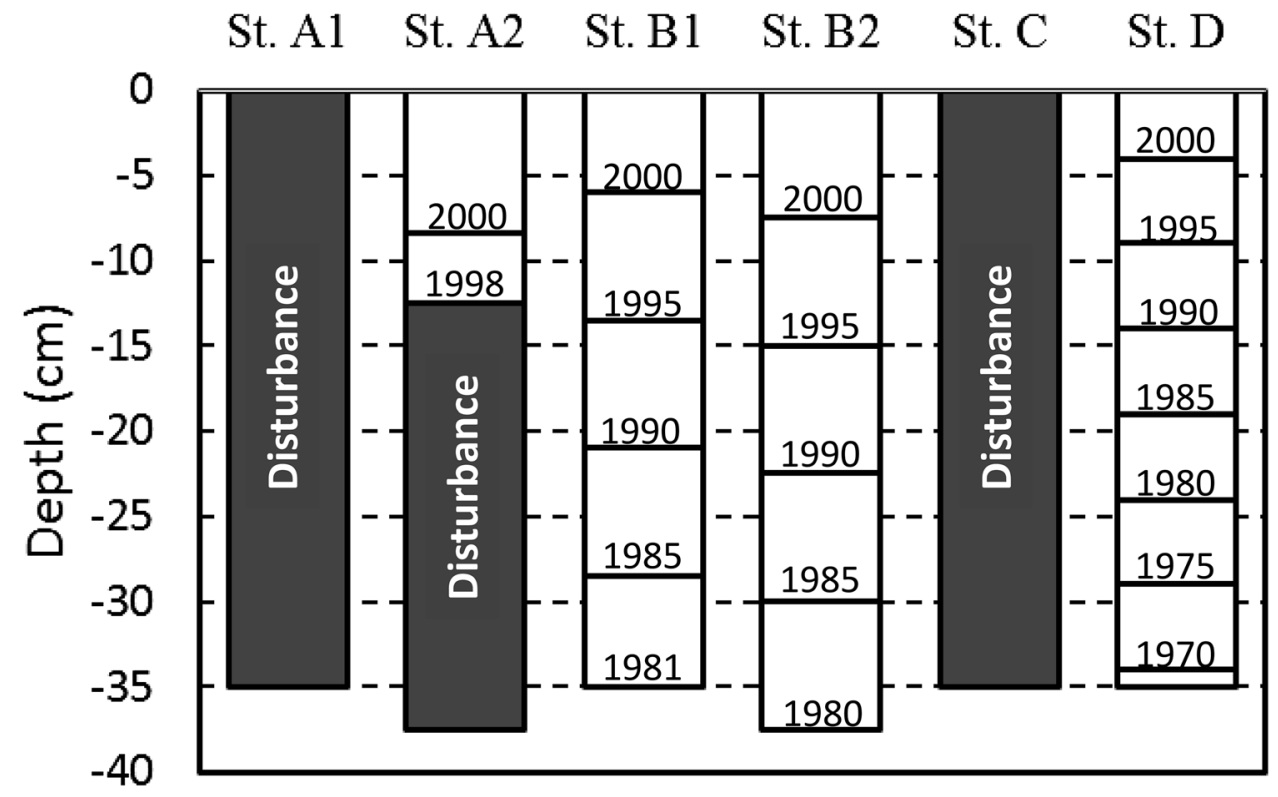

up to $8 \mathrm{~m}^{3} / \mathrm{s}$ into the upper part of Lake Teganuma. This dilution of LAS concentrations in the river and lake water is expected to reduce concentrations in the sediment as well. However, LAS concentrations in the sediment had already begun to decrease in the late 1990s at St. A2 and in the late 1980s at Sts. B1 and B2 (Fig. 3a, b). Therefore, it is obvious that the expansion of sewer coverage played a major role in the reduction of LAS in the lake sediment before 2000. Moreover, the decrease in the COD value of the lake water [14], which began in the mid-1990s (Fig. 3e), is also consistent with this interpretation. The injection of Tone River water into Lake Teganuma might also be expected to resuspend polluted bottom sediments, but such resuspension in the lake has been reported to be negligibly small [28].

\section{Conclusions}

The amounts of synthetic detergent surfactants adsorbed onto bottom sediments near the mouths of the Oohori and Ootsu rivers and in the center of Lake Teganuma well reflected changes in contamination of the lake and river waters by domestic wastewater from the basin, and countermeasures implemented to reduce that contamination, over a 30-year period. Our results show that concentrations of synthetic chemicals recorded in lake bottom sediments, particularly of chemicals such as LAS, which are used and discharged daily in quantifiable amounts, provide important clues about past contamination levels as well as about changes in the social environment in the lake basin.
Acknowledgements The authors thank Dr. Taeko Doi and Dr. Kazuo Matsushige, former researchers at the National Institute for Environmental Studies, for their help in collection of the sediment core samples. We also thank the Teganuma Sewer Office and Teganuma Wastewater Treatment Plant for permission to collect samples at the plant and help during the sampling. One of the authors (KI) thanks Dr. Hisako Ogura, former researcher of the Chiba Prefectural Laboratory of Water Pollution, for helpful comments at the beginning of the study.

\section{Compliance with ethical standards}

Conflict of interest The authors declare that they have no conflict of interest.

\section{References}

1. Latimer JS, Quinn JG (1996) Historical trends and current inputs of hydrophobic organic compounds in an urban estuary: the sedimentary record. Environ Sci Technol 30:623-633

2. Isosaari P, Pajunen $\mathrm{H}$, Vartiainen $\mathrm{T}$ (2002) PCDD/F and PCB history in dated sediments of a rural lake. Chemosphere 47:575-583

3. Zushi Y, Tamada M, Kanai Y, Masunaga S (2010) Time trends of perfluorinated compounds from the sediment core of Tokyo Bay, Japan (1950s-2004). Environ Pollut 158:756-763

4. Ratia H, Oikari A (2014) Vertical distribution of AhR-activating compounds in sediments contaminated by modernized pulp and paper industry. Water Res 50:27-34

5. Inaba K (1992) Quantitative assessment of natural purification in wetland for linear alkylbenzenesulfonates. Water Res 26:893-898

6. Shimizu N, Koga T, Moriyama S, Tsuchida D, Fujikawa K, Tanaka Y (2015) Pollution loads of linear alkyl benzene sulfanate from household detergents. Annu Rep Fukuoka Inst Health Environ Sci 42:80-85

7. Takada H, Ishiwatari R, Ogura N (1992) Distribution of linear alkylbenzenes (LABs) and linear alkylbenzenesulfonates (LAS) in Tokyo Bay sediments. Estuar Coast Shelf Sci 35:141-156 
8. Zeng EY, Khan AR, Tran K (1997) Organic pollutants in the coastal marine environment off San Diego, California. 3. Using linear alkylbenzenes to trace sewage-derived organic materials. Environ Toxicol Chem 16:196-201

9. Inaba K, Shiraishi H, Soma Y (1998) Source and material balance of total organic halogen pollution in the Ayase River system, Japan. Toxicol Environ Chem 67:391-407

10. Maki H, Tokuhiro K, Fujiwara Y, Ike M, Furukawa K, Fujita M (1996) Biodegradation of synthetic surfactants by river microorganisms. J Environ Sci 8:275-284

11. Scott MJ, Jones MN (2000) The biodegradation of surfactants in the environment. Biochim Biophys Acta 1508:235-251

12. Merrettig-Bruns U, Jelen E (2009) Anaerobic biodegradation of detergent surfactants. Materials 2:181-206

13. Jurado E, Fernandez-Serrano M, Rios F, Lechuga M (2013) Aerobic biodegradation of surfactants. In: Chamy R (ed) Biodegradation life of science, Chapter 3. IntechOpen Ltd., London, pp 63-81

14. Chiba Prefectural Government (2018) Lake Teganuma water cycle recovery action plan (revised edition), pp 43. www.pref. chiba.Ig.jp/suiho/kasentou/teganuma/documents/zenbun.pdf. Accessed 10 Aug 2018

15. Inaba K, Amano K (1988) HPLC determination of linear alkylbenzenesulfonate (LAS) in aquatic environment. Seasonal changes in LAS concentration in polluted lake water and sediment. Int J Environ Anal Chem 34:203-213

16. Amano K, Fukushima T, Inaba K, Nakasugi O (1989) Adsorption of linear alkylbenzenesulfonates with the suspended solids in natural aquatic systems. Jpn J Water Pollut Res 12:506-515

17. Amano K, Fukushima T, Nakasugi O (1990) Evaluation and prediction of linear alkylbenzenesulfonates (LAS) in water and sediment. Environ Sci (Jpn) 3:177-186

18. Chiba Prefectural Government (2003) Teganuma water cycle recovery action plan, Document 4: major projects related to the purification of water quality in Teganuma and its results. www. pref.chiba.lg.jp/suiho/kasentou/inbanuma/mizujunkan/docum ents/siryo4.pdf. Accessed 10 Aug 2018

19. Tokyo Metropolitan Government Bureau of Sewerage (2015). Annual report on technical survey 2-2-2. Survey on the actual condition of chemical substances at the water reclamation center, pp 9. www.gesui.metro.tokyo.jp/business/pdf/2-22_2015.pdf. Accessed 10 Aug 2018

20. Chiba Prefectural Laboratory of Water Pollution (1984) Sediment of Lake Teganuma-sedimentation and characteristic of polluted mud. Chiba Prefectural Laboratory of Water Pollution Report No. 39

21. Hamada T, Motohashi T, Watanabe M, Ito H (2006) Chronosequencial analysis of eutrophication and heavy metal pollution recorded in sediments of Lake Teganuma, Chiba Prefecture, Japan. J Geogr 115:26-40

22. Chiba Prefectural Government (2018) Outline of Teganuma sewerage treatment plant. www.pref.chiba.lg.jp/gs-teganuma/jigyo u/gaiyou.html. Accessed 10 Aug 2018

23. Inaba K, Sudo R (1988) Per capita loadings of synthetic detergents in gray water. Res Rep Nat'l Inst Environ Stud 116:25-38

24. Fukuyo K (2004) Estimation of energy and water consumptions for various life styles. J Soc Heat Air Cond Sanit Eng Jpn 78:237-240

25. Chiba Prefectural Government (2016) Proper use of sewer. www. pref.chiba.Ig.jp/gesui/jigyou/koshou/documents/seibikouka .pdf. Accessed 10 Aug 2018

26. Abiko City Hall (2015) Frequently asked questions on life and procedures. www.city.abiko.chiba.jp/kurashi/faq/shizen/tegan uma/jyuoka1.html. Accessed 10 Aug 2018

27. Abiko City Hall (2016) Water purification measures in Lake Teganuma. Annual Environ. Rep. Part 2-1, p 33. www.city.abiko.chiba .jp/anshin/kankyo_kougai/kankyonenpo/kankyounenpou 20 16.files/teganumanosuisituzyoukataisaku.pdf. Accessed 10 Aug 2018

28. Kano A, Taki K (2009) Analysis on influence of Kita-Chiba conveyance on the flow and sediment of Lake Teganuma. In: Civil Engineering Association Kanto Branch 36th technical research conference VII-57

Publisher's Note Springer Nature remains neutral with regard to jurisdictional claims in published maps and institutional affiliations. 